\title{
EMPREENDEDORISMO RURAL: OLHARES EM CONTEXTOS DIVERSOS
}

\section{RURAL ENTREPRENEURSHIP: A LOOK INTO DIVERSE CONTEXTS}

\begin{abstract}
:
The article analyzes the trajectories of rural producers in order to point out the elements that bring them closer to the reality of rural entrepreneurship. The article contributes to the perception of rural entrepreneurship as an auxiliary tool in the creation and distribution of wealth as well as to socioeconomic development. The qualitative approach methodology adopted for the study is based on multiple case studies and on semistructured interviews to generate the data. Three entrepreneurial trajectories were analyzed in two Brazilian states: Minas Gerais and Rio Grande do Sul. The restriction to take risks may demonstrate a less common characteristic among rural entrepreneurs. However, the break with traditional techniques and the innovation in production processes, elaboration and distribution of products stands out in the three cases. Finally, it is possible to identify the approximation of trajectories to the notion of entrepreneurship as a process that benefits from opportunities.
\end{abstract}

Keywords: Rural entrepreneurship; Agriculture; Trajectories. 


\section{Introdução}

Estudar a ação empreendedora por meio de diferentes perspectivas de modo a considerar as atitudes dos indivíduos através de seu contexto requer o entendimento de que existem elementos que interferem no agir de tal indivíduo, como elementos culturais, históricos, sociais e econômicos. Tais particularidades subjazem as transformações que ocorrem no ambiente de trabalho (FUERSCHUTTE; GODOI, 2008). Assim, o impacto das modificações no espaço produtivo provoca desafios para os agentes que atuam em tal setor, sejam eles empreendedores, trabalhadores autônomos e/ou empregados.

Para os autores acima, o agente empreendedor destaca-se como detentor de certas características que lhes conduzem à eficiência e ao sucesso. Estes indivíduos enfrentam situações desafiadoras que se tornam como campos profícuos para disseminar suas ações empreendedoras. Segundo Fuerschutte e Godoi (2008), as particularidades dos empreendedores são elementos que se difundem em contextos específicos e, quando aplicados à realidade de cada espaço, podem ser dinamizados de modo a aumentar sua efetividade.

Pensando nisso, esse artigo direciona-se a iniciativas empreendedoras no espaço rural e algumas das particularidades encontradas nesse ambiente. Levando em conta essas especificidades, por vezes, os referenciais que associam empreendedorismo e rural reproduzem a literatura pensada para ambientes urbanos e industriais, desconsiderando, ou ao menos encobrindo, elementos que poderiam ser considerados próprios do empreendedorismo rural.

Nessa linha, Müller e Korsgaard (2017) trazem contribuições que concordam com a ideia apresentada, pois os autores destacam que o contexto espacial e os recursos disponíveis são importantes variáveis para o delineamento das atividades do empreendedorismo. A performance do empreendedor é costumeiramente influenciada pelos seus traços pessoais como também pelo contexto das suas redes e imersão social (CORRÊA; VALE, 2014). Especialmente no meio rural, a decisão do que produzir, como produzir, com quem estabelecer redes de colaboração e determinar quais mercados atender está diretamente influenciada pela inserção dos agricultores em seus contextos locais.

A suposição da influência do contexto para a ação empreendedora torna-se ainda mais atrativa para a trajetória empreendedora de grupos de baixa extração social, visto que muitos conseguem superar diversos empecilhos, a fim de atuar no ambiente empresarial (CORRÊA; VALE, 2014). Para os autores, a investigação de como ocorre este fenômeno é fundamental para compreender o desempenho destes empreendedores.

Desta forma, este artigo tem como objetivo analisar três trajetórias sociais inseridas no rural, em distintas regiões brasileiras, e, assim, apontar elementos que as aproximem da realidade do empreendedorismo rural. Esse esforço é realizado sob a justificativa, trazida por Dolabela (2003), de contribuir para a percepção do empreendedorismo como uma ferramenta para auxiliar na criação e distribuição das riquezas e no desenvolvimento humano e social. Para tanto, busca-se avançar nas diferentes perspectivas do empreendedorismo, perpassando as preocupações de estudar alguém que cria uma empresa (DOLABELA, 2003), para entender as distintas formas de empreender no rural.

Aparentemente, as realidades trazidas neste artigo são distintas, mas guardam elementos em comum, os quais são tratados como aspectos potenciais para uma compreensão introdutória que auxilia no entendimento do empreendedorismo em um ambiente, de certa forma, pouco discutido; o rural e suas múltiplas formas de descortinar, o que pode ser percebido como particularidades de um empreendedorismo singular ao seu modo de manifestar-se.

\section{Empreendedorismo}

Os debates que norteiam a temática do empreendedorismo expressam distintas definições sobre quem é o agente empreendedor, contudo, estas discussões têm em comum o entendimento de que se trata de um indivíduo com características peculiares, que transforma o ambiente em que atua. Para Baggio e Baggio (2014), o empreendedor busca a mudança, responde e explora esta mudança por meio do aproveitamento de uma oportunidade. Corroborando com a ideia, Dornelas (2008) afirma que o empreendedorismo se caracteriza pelo envolvimento de pessoas e processos, que em conjunto transformam ideias em oportunidades e o aproveitamento de oportunidades leva à constituição de negócios de sucesso.

O empreendedorismo resulta de agentes empreendedores que conseguem realizar determinadas ações em decorrência de sua sensibilidade para os negócios e da sua habilidade em constatar e aproveitar as oportunidades que lhes surgem, mesmo não sendo claras e específicas (CHIAVENATO, 2012). Por possuir criatividade e perseverança, o empreendedor converte ideias em ações reais que visam vantagens pessoais ou para a sociedade, de modo a produzir resultados consistentes para a comunidade e mercado.

Perante Filion (1999), o empreendedor é aquele indivíduo criativo, movido pela capacidade de alcançar seus objetivos e que busca detectar oportunidades de negócios. É um agente que toma decisões arriscadas, a fim de desempenhar seu papel de empreendedor, ou seja, é a pessoa que imagina, desenvolve e realiza visões.

No que se refere às características empreendedoras, a escola economicista, que tem dentre seus principais expoentes Joseph Schumpeter (1985), alude que o empreendedor é aquele que destrói a ordem econômica através da introdução de novos produtos ou serviços. Para esta escola, o empreendedorismo está associado à inovação, ou seja, realizar algo novo e distinto do que existe (CHIAVENATO, 2012). Já para a escola comportamentalista, o empreendedor é aquele indivíduo que possui capacidade motivacional em virtude da sua necessidade de realização e da sua autoconfiança, o empreendedor busca algo novo que satisfaça seu desejo e seus sonhos (CHIAVENATO, 2012).

Posto isto, nota-se que o estudo sobre o empreendedorismo abarca distintos campos de investigação. Um dos campos mais recentes de discussões é o do empreendedorismo rural. $\mathrm{O}$ debate 
sobre a ação empreendedora no rural e como ela se desenvolve em um ambiente caracterizado como não empreendedor motiva estudos e pesquisas em diferentes países.

\section{Ação Empreendedora}

A ação empreendedora se refere à "capacidade de gerar novos conhecimentos a partir de uma base da experiência de vida do indivíduo" (DOLABELA, 2003, p.22). Para complementar, McMullen e Sheperd (2006) mencionam que a ação empreendedora sugere que há uma intenção, pois quando um comportamento expressa essa ação, a intenção ou os desejos estão necessariamente implícitos. A intenção empreendedora pode ser compreendida como uma força motriz que direciona e impulsiona processos empreendedores fundamentados na descoberta e/ou criação de oportunidades (CHA; BAE, 2010).

A intenção empreendedora, compreendida como a força mental que reconhece e centra-se em uma oportunidade, pode ser a motivação para a sequência de um caminho de incertezas, em que energiza e orienta o comportamento empreendedor para enfrentar obstáculos. Desta forma, a intenção empreendedora poderá estimular os processos de inovação, a construção da organização e a busca por investimentos (CHA; BAE, 2010).

Não havendo a conversão da intenção empreendedora em ação empreendedora, pode-se constatar, possivelmente, a presença de barreiras, sejam normativas e regulamentares, socioculturais ou econômico-financeiras que a impediram (OLIVEIRA, 2016). Essa relação entre a intenção e a ação empreendedora conduz a discussão para a ideia de potencial empreendedor, pois este poderá, ou não, concretizar a conversão de uma para outra, estando em acordo com suas características e contexto. Desta forma, a noção de potencial empreendedor pode auxiliar a entender a associação entre produtores familiares e empreendedorismo rural, que, em um primeiro momento, parece distante, como apontam Tomei e Lima (2014).

\section{Potencial Empreendedor}

A dificuldade em delinear um perfil científico que contemple um quadro com as características empreendedoras tem estimulado, mais recentemente, estudos que optam por reconhecer o "potencial empreendedor". Nessa linha, Santos (2008) argumenta que os estudos de perfil empreendedor, até então, não podem ser considerados conclusivos, pois ao serem replicados em diferentes ambientes, os resultados distinguem-se dos anteriormente encontrados, até mesmo demonstrando elementos novos. Em suma, Santos (2008, p. 132) salienta que "a busca de um protótipo do empreendedor universal não tem apresentado resultados animadores".

Para Santos, Caetano e Curral (2010), a constituição do potencial empreendedor é baseada em competências, apontando que as possibilidades de estímulos à formação e ao desenvolvimento de tais competências se aproximam da realidade. Esta afirmação condiz com a defesa de Dolabela (2003, p. 24) quando menciona que "o espírito empreendedor é um potencial de qualquer ser humano", porém, "necessita de algumas condições indispensáveis para se materializar e produzir efeitos".

Pensando no contexto rural de investigação, parece que a ideia de potencial empreendedor se aproxima do que Tomei e Lima (2014) encontraram em sua pesquisa, ou melhor, agricultores apresentando algumas características empreendedoras e outras não, indicando a dificuldade em identificar um perfil específico do empreendedor rural. Assim, a ideia de potencial empreendedor traz elementos teóricos que auxiliam nas interpretações sobre o empreendedor rural.

Adicionalmente, as configurações do empreendedorismo em áreas rurais, influenciadas pela evolução do território rural expresso por mudanças demográficas, econômicas, culturais e de infraestrutura, refletido, por exemplo, pelo declínio da inserção de novos agentes na agricultura e movimentos da população em relação ao rural (MCELWEE; SMITH, 2014). Esses apontamentos direcionam o leitor a subseção seguinte, que traz discussões sobre o empreendedorismo no rural.

\section{Empreendedorismo Rural}

Cada vez mais, os agricultores estão inseridos em ambientes de constante competitividade e transformação, de modo que se torna importante tomar iniciativas com vistas a garantir a manutenção neste espaço (CHAVES, 2010). Atualmente, os produtores rurais buscam estratégias que visam a redução de custos, aumento de produtividade e diferenciação produtiva, as quais podem se converter em diferenciais frente às mudanças e exigências do ambiente econômico (CHAVES, 2010). Uma maneira de conseguir desenvolver estas estratégias é por meio da ação empreendedora.

Inicialmente, parece uma constatação errônea relacionar agricultores familiares ao empreendedorismo (TOMEI; LIMA, 2014). Todavia, estes agricultores conseguem empreender dentro de suas limitações, sejam elas econômicas, tecnológicas, ambientais e locacionais, de maneira a transformar sua realidade socioeconômica (TOMEI; LIMA, 2014). Para os autores, a ação empreendedora no meio rural está presente em pequenas ações, que dificilmente seriam consideradas empreendedoras no urbano, como por exemplo a extração do leite da vaca e sua transformação em queijo.

A identificação do surgimento de novos mercados e o conhecimento da utilização dos recursos naturais disponíveis oferecem ao agricultor elementos para a expansão da atividade econômica a ser desenvolvida em sua propriedade (SANTOS; SANTOS, 2006). Para os autores, o empreendedor rural é o indivíduo que consegue detectar as oportunidades em sua volta, enfrenta obstáculos, corre riscos, a fim de guiar sua atividade produtiva para o sucesso. 
Corroborando com a ideia acima, o empreendedor rural é aquele que busca a melhor maneira de organizar sua propriedade, seja ao procurar novos cultivos, melhores animais, tecnologias alternativas, com o intuito de expandir a produtividade e estabelecer estratégicas de redução de custos (KAHAN, 2012). Assim, é preciso despertar o espírito empreendedor nos agricultores familiares para motiválos a descobrir potencialidades não exploradas em suas propriedades, que podem se tornar fonte de geração de renda (SANTOS; SANTOS, 2006).

Os agricultores empreendedores agem em um ambiente complexo e dinâmico e fazem parte de um conjunto de atores que engloba fornecedores, comerciantes, transportadores, processadores, cada um com suas determinadas funções (KAHAN, 2012). Dessa forma, um dos fatores fundamentais para o empreendedorismo rural é a capacidade do produtor rural de interferir no ambiente social, de modo a não atuar como um agente passivo das transformações do ambiente que está inserido (CHAVES, 2010).

\section{Procedimentos metodológicos}

O trabalho tem caráter descritivo, pelo fato de retratar características de determinado fenômeno ou população, com correspondência de variáveis (VERGARA, 2000). Segundo Malhotra (2001, p. 155), "a pesquisa qualitativa proporciona melhor visão e compreensão do contexto do problema, enquanto a pesquisa quantitativa procura quantificar os dados e aplica alguma forma da análise estatística". Dentro da pesquisa qualitativa, três são as abordagens - estudo de caso, pesquisa documental e etnografia -, e para o presente trabalho a abordagem escolhida foi o estudo de casos múltiplos. "Em um estudo de casos múltiplos, um dos objetivos que se tem em mente é elaborar uma explanação geral que sirva a todos os casos particularmente, embora possam variar em seus detalhes" (YIN, 2001, p. 142).

Tanto a abordagem quanto o tipo de pesquisa justificam-se pelo fato de buscarem entendimento acerca do problema de pesquisa, assim como procurarem obter maior conhecimento dos aspectos que não podem ser facilmente observados e medidos de forma direta, tais como sentimentos, pensamentos, intenções e comportamentos (AAKER; KUMAR; DAY, 2001).

A investigação proposta envolve dois estados brasileiros, apresentando três casos distintos que, no final dos resultados, se complementam, um em Minas Gerais e dois no Rio Grande do Sul. Em Minas Gerais, foi entrevistado um produtor da atividade pecuária e no Rio Grande do Sul outros dois entrevistados, um pecuarista e uma produtora rural da agroindústria. $\mathrm{Na}$ Figura 1 são demonstrados os estados, cidades e municípios dos estudos.
Figura 1 - Regiões pesquisadas.

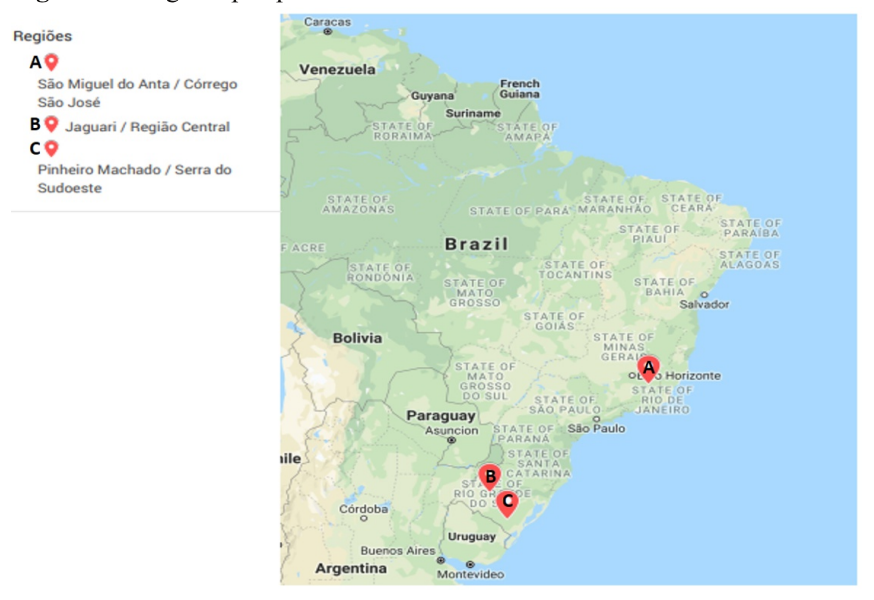

Fonte: Adaptado Google Maps (2019).

A amostra é intencional, segundo Flick (2009), na maioria dos casos, a amostragem na pesquisa qualitativa não é orientada por uma seleção formal de uma parte da população existente ou suposta. Esta população é escolhida como forma de estabelecer informações deliberadamente selecionadas para se construir um corpus de exemplos empíricos, com vistas a estudar o fenômeno de interesse da maneira mais construtiva (FLICK, 2009).

A técnica de coleta de dados foi a entrevista semiestruturada. Na visão de Triviños (2007), as entrevistas semiestruturadas partem de certos questionamentos básicos, formulados a partir do suporte teórico e de todas as informações coletadas sobre o fenômeno estudado.

\section{Resultados}

\section{Trajetórias Empreendedoras na Agroindústria Familiar Rural}

O presente estudo de caso foi realizado em uma agroindústria familiar rural do município de Jaguari/RS, localizado na região central do Estado do Rio Grande do Sul. O empreendimento agroindustrial existe há mais de 20 anos, e inicialmente era administrada pelo casal, a agricultora tem 55 anos de idade e o marido 60 anos. Atualmente, o empreendimento está sob a responsabilidade da agricultora, visto que seu marido cuida da produção de nozes.

Desde que residem na propriedade, a família planta uva. Inicialmente, toda a produção era entregue para uma cooperativa da cidade e, após alguns anos, o casal visualizou na produção de vinhos uma oportunidade de agregar valor à produção como alternativa para melhoria de geração de renda. Assim, os proprietários constituíram uma agroindústria familiar, que inicialmente operava na informalidade e logo após o empreendimento foi legalizado. Nota-se que a iniciativa da família pode ser interpretada como ação empreendedora, como destacam Gomes, Lima e Cappelle (2013).

No começo, a agroindústria era voltada somente para a produção de vinhos; com o passar dos anos, a 
agricultora começou a elaborar geleias e compotas de uva, e começou a vender em sua residência. Tal estratégia adotada pela gestora proporcionou um acréscimo de renda, visto que muitos clientes que iam até a agroindústria para comprar vinho acabavam adquirindo os doces também.

Após parar com a comercialização de vinhos, devido às inúmeras exigências a serem cumpridas para manter a produção legalizada, a produtora rural expandiu sua produção de geleias e compotas, bem como começou a produzir bolos e biscoitos, ao passo que seu marido iniciou uma plantação de nozes para posterior beneficiamento na propriedade. Neste ambiente situacional, a agroindustrialização destaca-se como aproveitamento de uma oportunidade pela família, uma vez que identificaram a possibilidade de agregar valor às frutas existentes na propriedade. Tal fato demonstra características empreendedoras dos produtores rurais, visto que tiveram a iniciativa de constituir um empreendimento agroindustrial em uma propriedade rural que, até então, comercializava sua produção de uva in natura.

No ano de 2015, a agricultora começou a disponibilizar serviço de cafés para eventos e aniversários, constituído de bolos, bolachas, salgadinhos, pizzas, chás, sucos e cafés. A ideia da produtora rural consiste em disponibilizar produtos diferentes dos costumeiramente encontrados nos eventos da região, prezando pela sua qualidade e frescor. Para a produtora, a decisão de oferecer cafés em eventos parte da identificação da ausência deste tipo de serviço no município e da necessidade de suprir tal lacuna.

A oferta de cafés para eventos demonstra características empreendedoras, como a identificação de uma oportunidade e a inovação em disponibilizar algo inédito na cidade. Para Schumpeter (1985), a ação empreendedora se caracteriza através de inovações que transformam a dinâmica de um setor ou atividade, de modo a promover uma ruptura nos fluxos econômicos existentes. Tal reflexão é constatada na agroindústria, em virtude de a introdução dos cafés modificar a situação econômica do empreendimento e garantir a sua manutenção, uma vez que a proprietária afirma que foi por meio destes novos serviços que a situação financeira da agroindústria melhorou.

Outra inovação desenvolvida pela agricultora foi a introdução de produtos diferenciados para determinado público-alvo, ou seja, a proprietária começou a produzir alimentos sem glúten e integrais. Tal iniciativa possibilitou ao empreendimento familiar expandir o número de clientes, em virtude de conseguir atender uma nova parcela do mercado. A identificação desta lacuna destaca-se também como aproveitamento de uma oportunidade, uma vez que se refere ao indivíduo estar atento ao que acontece em sua volta, identificar as necessidades das pessoas ou mercados e, a partir dessas lacunas, começar novas atividades (MARTINS, 2013).

Percebe-se que a produtora rural não exerce a atividade agroindustrial somente pelo retorno financeiro, mas por gostar do que faz.

Eu gosto daquilo que eu faço, a gente trabalha com amor, eu sempre digo, os nossos produtos são feitos com amor, e dai tudo muda...Eu to trabalhando em uma coisa que me dá prazer, não vou trabalhar em uma coisa que não me dá prazer. (ENTREVISTADA).
Este sentimento pelo trabalho realizado faz com que a produtora se sinta motivada a exercer suas atividades da melhor maneira possível, a fim de sanar as necessidades de seus consumidores.

\section{Trajetória Empreendedora no Rural em Minas Gerais}

A pecuária em Minas Gerais é muito diversificada e tradicional, a região referente a este trabalho é a mesorregião da Zona da Mata Mineira, no município de São Miguel do Anta, uma região que tem como destaque a pecuária leiteira. Atualmente, esta região é formada por 142 municípios inseridos em 7 microrregiões (IBGE, 2010). Na propriedade pesquisada, a produção é integramente dedicada ao gado de corte, especificamente recria de bezerros.

A trajetória deste pecuarista na atividade teve início no ano de 2016, o entrevistado não reside na propriedade, encarregando seu pai, sr. José, que mora em terreno limítrofe, como responsável pela propriedade. O sr. José tem como função gerenciar a manutenção da cerca, vacina e limpeza das pastagens, e para a realização destas atividades é contratada mão de obra terceirizada, com uma frequência de três em três meses. O pecuarista é casado, tem 34 anos, graduado pela Universidade Federal de Viçosa/MG no curso Gestão de Cooperativas, concluído no ano de 2012, e possui experiência profissional em áreas como administração, gestão e empresarial.

O entrevistado nasceu da região da Zona da Mata Mineira, morou até os 24 anos na propriedade do pai (que hoje faz divisa com sua propriedade), com sua família, que era de produtores familiares. Aos 24 anos, o entrevistado foi para a cidade vizinha Viçosa, cursar a graduação. Ao finalizar o curso, foi trabalhar como empresário em uma cidade no Triângulo Mineiro, Uberaba, mas sua paixão em ter sua propriedade estava presente, sendo assim, destinou parte de sua renda para comprar terras próximas à propriedade de seus pais.

A propriedade rural possui 77 hectares destinados à recria do gado de corte das raças Girolando e Nelore. "A raça Girolando é uma raça sintética, bimestiça, desenvolvida no Brasil a partir do cruzamento de Holandês com o Gir Leiteiro, tendo a composição de $5 / 8 \mathrm{H}$ e $3 / 8$ Gir (ou simplesmente $5 / 8$ HZ)" (MIRANDA; FREITAS, 2009, p. 2). É uma raça que possui duplos destinos, para a carne e o leite, adaptada a regiões tropicais e subtropicais. Segundo Mezzadri (2007, p.38), "a raça nelore se caracteriza, de forma geral, por animais de porte médio a grande, de pelagem branca, cinza e manchada de cinza". Trata-se de uma raça destinada a ofertar carne para consumo interno e externo do Brasil, representando o gado Nelore $80 \%$ do gado produzido no país.

Segundo o entrevistado, sua propriedade tem aproximadamente 70 animais, com dois anos de atividade. As pastagens são formadas de campo nativo, sendo áreas de morro recuperadas com o plantio de Brachiaria decumbens. Esta planta é popularmente conhecida como capim-braquiária, possui grande capacidade de se adaptar a solos de baixa fertilidade, proporcionando boa cobertura do solo. (JAKELAITIS 
et al., 2004). O processo de reprodução acontece com a compra de bezerros, que passam pela recria, levando para venda os garrotes. A venda dos garrotes é para terceiros (frigorífico e açougue) da região.

Em sua fala, o entrevistado relatou que pretende aumentar a sua área de pastagens, e tem como objetivo o melhoramento genético, para que futuramente possa ampliar seu mercado consumidor. Um ponto importante a ser salientado é a familiarização do pesquisado com a atividade rural desenvolvida em conjunto com sua experiência acadêmica, mesclando elementos para a formação de um contexto espacial favorável para o desenvolvimento de características empreendedoras (MÜLLER; KORSGAARD, 2017). A imersão social, segundo Corrêa e Vale (2014), acontece desde criança neste universo rural, auxiliando no desenvolvimento de atividades empreendedoras. Um ponto que se diferencia das demais propriedades da região é o fato de que, em sua propriedade, é desenvolvida apenas uma atividade, demonstrando uma ruptura na forma tradicional de se criar gado de corte no município de São Miguel do Anta. Outro fator é a preservação de mata nativa e das nascentes de água, priorizando a preservação do meio ambiente.

Em entrevista, o pecuarista revela que a região é formada, na sua maior parte, de pequenas propriedades, tradicionalmente composta por agricultores e pecuaristas familiares, com diversificação de produção (gado de corte e leite, café, milho, feijão, tomate, moranga, banana e frango). As propriedades vizinhas possuem, em média, de 5 a 10 hectares, com diversidade de cultivos, não sendo especialistas na monocultura.

Ao longo da entrevista, pode ser observado que este pecuarista apresenta práticas inovadoras em suas atividades, uma vez que faz investimentos em melhoramento genético e na recuperação de pastagens, para não faltar alimentação abundante para o gado na época da seca (período de maio a setembro). Aponta também que faz a rotação de animais, em forma de piquetes, e a suplementação mineral dos mesmos, desta forma, estas inovações demonstram um interesse do entrevistado em solidificar suas intenções em ações, pois no rompimento com a lógica tradicional podem ser percebidas oportunidades estimuladas por processos de inovação (CHA; BAE, 2010).

Com o intuito de destacar a importância das características empreendedoras, durante a entrevista foi perguntado sobre a questão do aprendizado, importante fator para atitudes inovadoras. O entrevistado declarou que busca sempre se atualizar, acreditando que:

[...] a tecnologia e a globalização muda tudo todos os dias, tem que acompanhar essas mudanças, se não seu negócio cai no esquecimento [...].busco sempre me manter atualizado, procuro entender economia e política principalmente, conhecimento cientifico já é mais complicado, por que necessita de mais tempo e dedicação, mais sei da necessidade para aperfeiçoar meus conhecimentos [...]. (ENTREVISTADO 2).

Visto isso, fica evidenciado seu interesse em buscar aperfeiçoamento e o interesse em aprender sobre seu negócio, compartilhando experiências e realizando leituras de livros e artigos a respeito da pecuária de corte. Outra característica importante para identificar um empreendedor seria a sua persistência em manter seu negócio. Para tanto, foi perguntando se empreender no rural precisa de muita persistência, ao que ele revelou que sim, como pode ser ressaltado no trecho a seguir:

\section{[...] acredito ser dificil, porque os filhos de pecuaristas na sua grande maioria precisam mudar as atividades da propriedade quase que completa, $e$ enfrentam a resistência da família, gerando conflitos de opinião e ideias, bem dificil quebrar o sistema tradicional, por isso ter persistência é fundamental". (ENTREVISTADO 2).}

Considerando que a adaptação seja uma característica importante no empreendedor, durante a entrevista foi questionado se o processo de adaptação foi muito longo para ele, e o entrevistado disse que sim, porém destacou: "tentei fazer algumas adaptações, mas encontrei muita resistência do meu pai, isso acabou adiando meus planos. Voltei a ser empreendedor depois dos 30 anos, já na minha propriedade".

Deste modo, foi verificado que, por alguns anos, ele tentou empreender na propriedade do pai, porém não conseguiu obter sucesso, por se deparar com muita resistência. Por isso, buscou muito conhecimento e aprimoramento para colocar em prática seus objetivos. Apesar de seu pai cuidar da sua propriedade, em momentos de ausência, a troca de experiências acontece de forma lenta, pois seu pai mantém na sua fazenda os modos antigos de recria do gado de corte, dando prioridade ao gado de leite, uma vez que na região de São Miguel do Anta a pecuária leiteira é predominante.

Outro ponto importante foi entender como o meio (social, político, econômico, ambiental) consegue influenciar o processo empreendedor do sujeito. Na fala do entrevistado, ele acredita ser mais difícil o ambiente se adaptar ao seu negócio, uma vez que isso se daria a longo prazo, sendo mais simples se adaptar ao meio. Consequentemente, o planejamento é fundamental para o bom andamento da propriedade, entendendo-se que o planejamento acontece diariamente, como pode ser evidenciado nesta fala: "sem planejamento você não sabe como vai alcançar seus objetivos. Através do planejamento, você vai ter ideia de tempo / custo/ retorno / investimento etc." Destaca também que correr risco faz parte do processo: "o empreendedor não pode ter medo, se fazer com estudo e planejamento acho válido assumir esses riscos".

Assim, de maneira geral, foi perguntando quais foram as maiores dificuldades para desenvolver a atividade pecuária, ele revelou que teve de enfrentar a falta financeira no início, juntamente com a responsabilidade em fazer dar certo e, finalmente, o desafio em entender como funcionava a lógica do mercado.

\section{O entrevistado definiu empreendedorismo como} sendo:

\begin{abstract}
[...] Gosto de comparar empreender com desafio. Empreendedorismo é viver de seu negócio, todos os dias você tem que pensar por ele, trabalhar por ele, mudar por ele, isso não serve pra pessoas que tem medo de sair da sua zona de conforto, é buscar trabalhar com tecnologia, levar conhecimento cientifico pra dentro da propriedade, não ter medo de serviço [...]. (ENTREVISTADO).
\end{abstract}

Diante do exposto, nota-se que o entrevistado apresenta capacidade inovadora, buscando novos conhecimentos, procurando adaptar-se e entender o 
meio onde seu negócio atua, com consciência dos desafios diários e que correr riscos faz parte da vida de um empreendedor.

Pode-se concluir que o planejamento é um mecanismo indispensável para obtenção de bons resultados. Deste modo, Cella e Peres (2002) apontam para a importância do planejamento da produção e de todas as atividades a serem desempenhadas, tanto de curto prazo como de longo prazo. Destacam, também, ser fundamental o controle financeiro dos custos de produção e dos gastos com a manutenção das atividades rurais. Outra característica fundamental ao produtor rural empreendedor é a busca pelo melhoramento de competência, através de estudos necessários ao desenvolvimento de suas atividades.

\section{Trajetórias Empreendedoras na Pecuária Familiar no Rio Grande do Sul}

A pecuária familiar encontrada na Metade Sul do Rio Grande do Sul tem sido questionada quanto à sua relação com temáticas como inovação e empreendedorismo rural. Dada a formação socioeconômica e histórica da região, as grandes propriedades agropecuárias ficaram conhecidas como a principal atividade rural produtiva desenvolvida, onde são observados "baixo crescimento econômico, estrutura fundiária concentradora e pouco espírito empreendedor" (CORONEL; ALVES, 2007, p. 73). No entanto, Ribeiro (2009) mostra outra face da pecuária da Metade Sul, a pecuária familiar.

Nesse rol de heterogeneidades, por vezes desconhecido, a trajetória apresentada revela elementos potenciais que poderiam definir peculiaridades de um empreendedor rural dedicado à criação de gado de corte. O pecuarista entrevistado reside na propriedade, no interior do município de Pinheiro Machado/RS, possui o ensino médio incompleto e 44 anos. Com ele residem sua esposa de 48 anos e uma filha de 16 anos, estudante do ensino médio, compondo a mão de obra familiar da propriedade rural. Em algumas ocasiões, como esquila, limpeza de campo, ocorrem contratações temporárias.

A propriedade rural é procedente de herança recebida do pai e a família está há 7 anos na propriedade. A área da propriedade totaliza 233 hectares distribuídos na criação integrada de gado de corte, ovinos e cavalos destinados aos serviços e campo. Em 7 anos de atividade, o rebanho bovino apresenta, aproximadamente, 200 animais, entre vacas, novilhas e terneiros (bezerros), 350 ovinos, destes 100 cordeiros destinados à venda, e 10 cavalos também destinados à venda e eventuais trocas entre produtores.

É nesse panorama que o produtor destaca a aptidão produtiva da região para a criação de bovino de corte e ovino de corte e lã. Segundo o entrevistado, na região encontram-se grandes estâncias que se dedicam exclusivamente à pecuária de corte, assim como propriedades menores que permanecem somente com a pecuária de corte, isentas de arrendamento de terras para atividade agrícola, como lavouras de soja e arroz, ou melhor, que apresentam características que as definem como tradicionais, mantendo padrões de produção pouco aceitos pelo mercado.
Por mais que o produtor apresente uma postura avessa em relação ao acesso às opções de crédito rural, característica recorrente ao que tange os pecuaristas familiares (RIBEIRO, 2009), ele revela, em suas falas, rupturas com uma lógica tradicional de manejo da lã de ovinos, assim como a conviç̧ão sobre a venda de gado jovem e preferência pela produção de fêmeas, por exemplo. Nota-se elementos que correspondem às atitudes empreendedoras, pois ao considerar o contexto em que o produtor se insere, são as pequenas inovações que fazem com que ele enxergue oportunidades em seu negócio, assim como no manejo dos seus animais. Isso se percebe na seguinte fala sobre manejos e rupturas com sistemas de produção mais tradicionais:

\begin{abstract}
Eu esquilo [tosquiar ou tosar] em outubro, mas a maioria esquila de novembro a dezembro pra parar a chuva e a lã ficar mais pesada. Eu acho que é ilusão também... Eu já sou do... certas coisas de antiguidade que tem ai que eu acho que não tem futuro. Outro negócio que se tu espera mais dois anos, um ano, tu vai vender por quase o mesmo preço (bovinos de corte). Tu vende um terneiro hoje a mil pila... e tu vai vender um boi por $1500 \mathrm{com}$ dois anos e o que tem que gastar em remédio, gasta mão de obra, gasta campo... (ENTREVISTADO).
\end{abstract}

Rocha (2000) aponta algumas especificidades sobre a racionalidade dos pecuaristas que estariam condicionando a adoção de novas técnicas na atividade, como a opção por rendimentos de baixo risco que garantam um padrão de vida satisfatório. Casos como o exposto apresentam situações alternativas que "denunciam" algumas ideias mais tradicionais de produção, apontando preferências produtivas calcadas na experiência de campo e no desenvolver das atividades. Nesse mesmo raciocínio, o entrevistado demonstra conhecimento de mercado ao indicar sua direção para o consumo de animais jovens, destacando que não adianta o produtor insistir na venda de animais com 6 a 7 anos que o mercado não absorverá. Essa percepção demonstra o que Dolabela (2003) comenta sobre a experiência como instrumento capaz de gerar novos conhecimentos.

Os pecuaristas também se apresentam, por vezes, resistentes à introdução de novos métodos de controle sanitário. Ao contrário, o entrevistado comenta sobre a experiência ao usar métodos mais naturais, como o controle de carrapatos com remédios homeopáticos à base de enxofre e alho. Nesse aspecto, a produção mais tradicional peca, conforme $\mathrm{o}$ entrevistado, no manejo com os chamados "banhos" (aplicação de produtos veterinários). Em sua maioria, os produtores não costumam fazer os "banhos" de forma adequada por consideram como gasto, porém o entrevistado demonstra a necessidade de proceder a eles para garantir a sanidade do rebanho.

Apesar da resistência para acessar o crédito rural, o produtor busca alternativas à produção, tanto em termos de negócio quanto de manejo do rebanho. Além disso, atua como intermediário na venda do gado, pois compra de seus vizinhos para fechar carga e revender em outro município. Em resumo, considerando o contexto, observa-se que o entrevistado se enquadra nesta categoria, ao mesmo passo que apresenta características que fogem à "curva", podendo ser reconhecido como um tipo específico de empreendedor rural ou como um potencial empreendedor, como indica Santos (2008). 


\section{Considerações finais}

Por meio dos relatos, é possível compreender que a ação empreendedora rural se apresenta de diferentes formas em cada atividade pesquisada. No ramo da agroindústria familiar gaúcha, as características empreendedoras que mais se destacaram foram a busca pela qualidade, o comprometimento, visto que a produtora procura oferecer produtos frescos, bem como a paixão pelo que faz. Destaca-se também a inovação desenvolvida pela produtora rural, uma vez que disponibiliza serviços não oferecidos por nenhum outro empreendimento na região e sua persistência devido ao fato de ter que adequar seu empreendimento no decorrer dos anos, a fim de conseguir se manter neste ramo.

Dentre as características empreendedoras que menos foram identificadas nos agricultores estudados destaca-se o correr riscos, pois o investimento em tecnologia ou aumento da produção decorre da expansão da demanda, visto que a produtora não investe sem ter certeza do retorno.

No meio rural no Estado de Minas Gerais, o caso observado apresenta reflexões importantes, uma delas seria como é difícil romper com os laços de negócios anteriores da família, uma vez que o entrevistado não conseguiu ser pecuarista quando morava com sua família, necessitando buscar novos conhecimentos, como cursar uma universidade, morar no urbano, fazer economias, comprar suas terras e o gado para ter seu negócio rural. A busca por novas práticas na pecuária, como melhoramentos genético do rebanho e das pastagens, são fatores essenciais para o bom andamento do negócio.

Vale ressaltar que o rural empreendedor pode passar por várias etapas em sua vida profissional, desde buscar um caminho diferente daquele vivenciado com sua família até buscar novos caminhos. Uma observação importante a ser feita sobre o empreendedor rural, diante deste caso em Minas Gerais, seria entender que a trajetória do empreendedor rural passa por várias etapas e processos e que persistência, planejamento, vencer medos, etc. são fundamentais para a vida do mesmo.

No caso apresentado da pecuária familiar no Rio Grande do Sul, a inovação em utilizar métodos de manejo diferenciados do contexto em que o pecuarista está inserido, assim como o reconhecimento de que algumas práticas tradicionais estão perdendo sua validade e viabilidade destacam-se ao buscar elementos que demonstrem ações empreendedoras na pecuária familiar. $\mathrm{O}$ conhecimento de mercado e, ainda, a compreensão de que a manutenção de técnicas tradicionais não preenche as lacunas de mercado permitem que sejam realizados ajustes/inovações na produção para atender os produtos da demanda. Em contrapartida, a predisposição em não correr riscos impede que o pecuarista realize operações de crédito, ficando os investimentos resguardados às suas reservas financeiras.

Em suma, trata-se de contextos diferentes que resguardam no rural o seu ponto em comum. As realidades apresentadas mostram trajetórias empreendedoras considerando seus ambientes de desenvolvimento, o que, em outras realidades não demonstrariam situações de empreendedorismo, ao considerar seus espaços de atuação, destacam-se como tais. Nota-se que a restrição a correr riscos pode, mesmo que de modo exploratório, estar se demonstrando como uma característica menos comum dentre empreendedores rurais. No entanto, a ruptura com técnicas remotas e a inovação - tanto em processos de produção quanto na elaboração e distribuição de produtos - destaca-se nos três casos apresentados.

Perante o exposto, espera-se que o presente artigo contribua para o debate de uma temática ainda em ascensão - o empreendedorismo rural. Pelos casos estudados, é possível perceber que a ação empreendedora está presente nas regiões do meio rural brasileiro estudadas nesta pesquisa, e que cada agricultor empreende na medida que é lhe possível, levando em consideração suas limitações econômicas, sociais, ambientais e culturais.

Sugere-se, para estudos futuros, a investigação do empreendedorismo em outras regiões que não foram pesquisadas por este artigo, a fim de se traçar um panorama do empreendedorismo rural no Brasil. O retrato destas ações possibilitaria a elaboração de ações específicas, através de entidades públicas e privadas, com o intuito de fortalecer o meio rural.

\section{Referências:}

AAKER, D. A.; KUMAR, V.; DAY, G. S. Pesquisa de Marketing. São Paulo: Atlas, 2001.

BAGGIO, A. F.; BAGGIO, D. K. Empreendedorismo: conceitos e definições. Revista de Empreendedorismo, Inovação e Tecnologia, Passo Fundo, v. 1, n. 1, p. 25-38, 2014.

CELLA, D.; PERES, F. C. Caracterização dos fatores relacionados ao sucesso do empreendedorismo rural. Revista da Administração, v. 37, n. 4, p. 49-57, 2002.

CHA, M. S.; BAE, Z. T. The entrepreneurial journey: from entrepreneurial intent to opportunity realization. Journal of High Technology Management Research, v. 21, p. 31-42, 2010.

CHAVES, R. Q. et al. Tomada de decisão e empreendedorismo rural: um caso da exploração comercial de ovinos de leite. Revista Brasileira de Gestão e Desenvolvimento Regional, Taubaté, v.6, n. 3, p.3-21, set./dez. 2010.

CHIAVENATO, A. Empreendedorismo: dando asas ao espírito empreendedor. 4. ed. Barueri: Manole, 2012.

CORONEL, D. A.; ALVES, F. D. A possibilidade de reconversão da Metade Sul do Rio Grande do Sul: algumas proposições à luz do modelo de desenvolvimento da Terceira Itália. Sociais e Humanas, Santa Maria, v. 20, n. 1, p.73-83, jan./jun. 2007.

CORRÊA, V. S.; VALE, G. M. V. Redes sociais, perfil empreendedor e trajetórias. Revista de Administração, São Paulo, v. 49, n. 1, p.77-88, jan./mar. 2014.

DOLABELA, F. Pedagogia empreendedora. São Paulo: Editora de Cultura, 2003.

DORNELAS, J. C. A. Empreendedorismo: transformando ideias em negócios. 3. ed. Rio de Janeiro: Elsevier, 2008. 
FILION, L. J. Empreendedorismo: empreendedores e proprietários-gerentes de pequenos negócios. Revista de administração, São Paulo, v. 34, n. 2, p. 5-28, abr./jun. 1999.

FLICK, Uwe. Desenho da pesquisa qualitativa. Porto Alegre: Artmed, 2009.

FUERSCHUTTE, S. G.; GODOI, C. K. Competência de empreendedores hoteleiros: um estudo a partir da metodologia da história oral. Turismo, Visão e Ação, Balneário Camboriú, v. 10, n.1, p. 39-55, jan./abr. 2008.

GOMES, A. F.; LIMA, J. B.; CAPPELLE, M. C. A. Do empreendedorismo à noção de ações empreendedoras: reflexões teóricas. Revista Alcance, Biguaçu, v. 20, n. 2, p. 203-220, abr./jun. 2013.

IBGE. Instituto Brasileiro de Geografia e Estatística. SIDRA: Território (2010). Disponível em:

https://sidra.ibge.gov.br/territorio\#/N8. Acesso em: 30 jun. 2019.

JAKELAITIS, A.; SILVA, A. A.; FERREIRA, L. R.; SILVA, A. F.; FREITAS, F. C. L. Manejo de plantas daninhas no consórcio de milho com capim-braquiária (Brachiaria decumbens). Planta Daninha, Viçosa-MG, v. 22, n. 4, p. 553-560, 2004.

KAHAN, D. Entrepreneurship in farming. Roma: FAO, 2012.

MALHOTRA, N. K. Pesquisa de Marketing: uma orientação aplicada. 3. ed. Porto Alegre: Bookman, 2001.

\section{MARTINS, D. R. Processo de decisão e}

empreendedorismo: Um estudo com empreendedores da região oeste de Santa Catarina. 2013. 97 f. Dissertação (Mestrado Profissional em Administração) - Fundação Pedro Leopoldo, Pedro Leopoldo, 2013.

MCELWEE, G.; SMITH, R. Researching rural enterprise. In:

FAYOLLE, Alain. (Ed.) Handbook of research on entrepreneurship: what we know and what we need to know. Cheltenham: Edward Elgar, 2014.

MCMULLEN, J.; SHEPERD, D. Entrepreneurial action and the role of uncertainty in the theory of the entrepreneur. Academy of Management Review, New York, v. 31, n. 1, p. $132-152$, jan. 2006.

MEZZADRI, F. P. Cenário Atual da Pecuária de Corte: Aspectos do Brasil com foco no Estado do Paraná. Curitiba: SEAB/DERAL/DCA, 2007.

MIRANDA, J. E. C.; FREITAS, A. F. Raças e tipos de cruzamentos para produção de leite. Circular Técnica, Juiz de Fora, EMBRAPA, n: 98, p. 1-12, 2009.

MULLER, S.; KORSGAARD, S. Resources and bridging: the role of spatial context in rural entrepreneurship. Entrepreneurship \& Regional Development, Lancaster, v. 30, n.1-2, p. 224-255, 2017.
OLIVEIRA, A J. M. Da intenção à ação empreendedora: uma avaliação empírica do impacto das principais barreiras. 2016. 79 f. Dissertação (Mestrado em Empreendedorismo e Internacionalização) - Instituto Superior de Contabilidade e Administração do Porto, Porto, 2016.

RIBEIRO, C. M. Estudo do modo de vida dos pecuaristas familiares da Região da Campanha do Rio Grande do Sul. 2009. 304 f. Tese (Doutorado em Desenvolvimento Rural) - Universidade Federal do Rio Grande do Sul, Porto Alegre, 2009.

ROCHA, J. M. As raízes do declínio econômico da "Metade Sul" do Rio Grande do Sul - uma análise da racionalidade econômica dos agentes produtivos da região. In:

JORNADAS DE HISTORIA REGIONAL COMPARADA, 1., Porto Alegre. Anais... Porto Alegre: FEE, 2000. p. 1-15.

SANTOS, P. C. F. dos. Uma escala para identificar potencial empreendedor. 2008. 366 f. Tese (Doutorado em Engenharia de Produção) - Universidade Federal de Santa Catarina, Florianópolis, 2008.

SANTOS, S. C.; CAETANO, A.; CURRAL, L. Atitude dos estudantes universitários face ao empreendedorismo: como identificar o potencial empreendedor? Revista portuguesa e brasileira de gestão, Rio de Janeiro, v. 9, n. 4, p. 2-14, out./dez. 2010.

SANTOS, W. S.; SANTOS, A. L. C. Perfil dos empreendedores que atuam no turismo rural na microrregião de feira de Santana (BA). In: CONGRESSO BRASILEIRO DE ECONOMIA E SOCIOLOGIA RURAL, 44., Fortaleza. Anais... Fortaleza: SOBER, 2006. p.1-15.

\section{SCHUMPETER, J. A. Teoria do desenvolvimento} econômico: uma investigação sobre lucros, capital, crédito, juro e o ciclo econômico. 2. ed. São Paulo: Nova Cultural, 1985.

STAKE, R. E. Case Studies. In: DENZIN, N. K. L.; YVONNA, S. L. (Orgs.). Handbook of Qualitative Research. 2. ed. London: Sage Publications, 2000. p. 10221040.

TOMEI, P. A.; LIMA, D. A. A. Análise das barreiras que dificultam a transformação do agricultor familiar em empreendedor rural no contexto brasileiro. Revista IberoAmericana de Estratégia - RIAE, São Paulo, v. 13, n. 3, p. 107-122, jul./set. 2014.

TOMEI, P. A.; LIMA, D. A. A. O empreendedor rural e a inovação no contexto brasileiro. In: CONGRESSO NACIONAL E EXCELÊNCIA EM GESTÃO, 15., Rio de Janeiro. Anais... Rio de Janeiro: CNEG \& INOVARSE, 2015. p.1-20.

TRIVIÑOS, A. Introdução à pesquisa em ciências sociais. São Paulo: Atlas, 2007.

VERGARA, S. C. Projetos e relatórios de pesquisa em administração. 3. ed. São Paulo: Atlas, 2000.

YIN, R. K. Estudo de caso: planejamento e métodos. 2. ed. Porto Alegre: Bookman, 2001. 